\title{
Budget impact analysis of two immunotherapy products for treatment of grass pollen-induced allergic rhinoconjunctivitis
}

This article was published in the following Dove Press journal:

ClinicoEconomics and Outcomes Research

10 September 2012

Number of times this article has been viewed

\author{
Steen M Rønborg' \\ Ulrik G Svendsen ${ }^{2}$ \\ Jesper S Micheelsen ${ }^{3}$ \\ Lars Ytte ${ }^{4}$ \\ Jakob $\mathrm{N}$ Andreasen ${ }^{5}$ \\ Lars Ehlers ${ }^{6}$ \\ 'The Pulmonology and Allergy \\ Clinic of Copenhagen, Copenhagen, \\ ${ }^{2}$ Bispebjerg Hospital, Copenhagen, \\ ${ }^{3}$ Private ENT practice, Aalborg, \\ ${ }^{4}$ General Practice Aalborg, ${ }^{5}$ ALK, \\ Hørsholm, ${ }^{6}$ Aalborg University, \\ Aalborg, Denmark
}

Background: Grass pollen-induced allergic rhinoconjunctivitis constitutes a large burden for society. Up to $20 \%$ of European and United States (US) populations suffer from respiratory allergies, including grass pollen-induced allergic rhinoconjunctivitis. The majority of patients are treated with symptomatic medications; however, a large proportion remains uncontrolled despite use of such treatments. Specific immunotherapy is the only treatment documented to target the underlying cause of the disease, leading to a sustained effect after completion of treatment. The aim of this study was to compare the economic consequences of treating patients suffering from allergic rhinoconjunctivitis with either a grass allergy immunotherapy tablet (AIT) or subcutaneous immunotherapy (SCIT).

Methods: A budget impact analysis was applied comparing SQ-standardized grass AIT (Grazax ${ }^{\circledR}$; Phleum pratense, 75,000 SQ-T/2,800 BAU; ALK, Denmark) with SCIT (Alutard ${ }^{\circledR}$; P. pratense, 100,000 SQ-U/mL; ALK, Denmark). Budget impact analysis included health care utilization measured in physical units based on systematic literature reviews, guidelines, and expert opinions, as well as valuation in unit costs based on drug tariffs, physician fees, and wage statistics. Budget impact analysis was conducted from a Danish health care perspective.

Results: Treating patients suffering from allergic rhinoconjunctivitis with grass AIT instead of grass SCIT resulted in a total reduction in treatment costs of $€ 1291$ per patient during a treatment course. This cost saving implies that approximately $40 \%$ more patients could be treated with grass AIT per year without influencing the cost of treatment.

Conclusion: Budget impact analysis showed that grass AIT is a cost-saving alternative to SCIT when treating patients with grass pollen-induced allergic rhinoconjunctivitis.

Keywords: grass pollen, allergic rhinoconjunctivitis, allergy immunotherapy tablet, subcutaneous immunotherapy, health economics, budget impact analysis

\section{Introduction}

Allergic rhinoconjunctivitis is a common allergic respiratory disorder caused by allergens such as grass or tree pollens and house dust mites. The prevalence of allergic rhinoconjunctivitis is increasing and is a major health issue worldwide. In Europe and the US, up to $20 \%$ of the adult population suffers from this condition. ${ }^{1-4}$ Allergic rhinoconjunctivitis is associated with symptoms such as a runny, blocked and/or itchy nose, sneezing, a gritty feeling in the eyes, and red/itchy/watery eyes, has a considerable impact on quality of life, and indirect costs arising from absenteeism from work and school, impaired sleep quality, and decreased productivity. ${ }^{5-9}$ Furthermore, allergic rhinoconjunctivitis is an independent risk factor for asthma or sinusitis. ${ }^{5}$ This increases the societal and economic impact of allergic rhinoconjunctivitis.
Correspondence: Jakob Nørgaard Andreasen

ALK, Bøge Alle I,

2970 Hørsholm, Denmark

Tel +4545747852

Fax +4545748690

Email jandk@alk-abello.com 
Treatment strategies for allergic rhinoconjunctivitis are largely symptomatic, and include oral antihistamines, nasal corticosteroids, and eye drops. ${ }^{10}$ However, the underlying allergic disease remains unaffected and symptomatic treatment offers only short-term relief.

Allergen-specific immunotherapy is the only treatment capable of activating immunomodulatory mechanisms and modifying the underlying course of the disease, thereby providing sustained relief of symptoms. ${ }^{11}$ Allergen-specific immunotherapy can be administered in different formulations, such as subcutaneous immunotherapy (SCIT) and allergy immunotherapy tablets (AIT).

SCIT has been widely used throughout Europe for decades. Treatment is initiated by a uptitration phase, during which the patient is given subcutaneous injections with increasing doses of allergen over a period of several weeks. This is followed by a maintenance phase during which the patient is given the maximum tolerated dose of allergen with each injection. More recently, AIT, a new and convenient form of immunotherapy, has been approved and marketed. AIT can be self-administered at home without uptitration.

The magnitude of and similarity in efficacy between these two treatment concepts has been and is still widely discussed. SCIT is documented to be efficacious and well tolerated in patients with grass pollen-induced allergic rhinoconjunctivitis. ${ }^{12}$ Sustained effectiveness of SCIT has also been demonstrated. ${ }^{13}$ Several trials have likewise confirmed the benefits of AIT treatment, with sustained efficacy and a favorable safety profile in patients with grass polleninduced allergic rhinoconjunctivitis. ${ }^{1-21}$

Direct comparisons between SCIT and AIT in clinical trials are still lacking, mainly because of the use of different treatment regimens and thereby difficulties in designing proper and ethical head-to-head comparisons. However, the efficacy of grass AIT and grass SCIT has recently been compared in a meta-analysis, ${ }^{22}$ which concluded that the clinical effect of grass AIT is similar in magnitude to that observed for SCIT in patients with grass pollen-induced allergic rhinoconjunctivitis of the same severity.

The international economic crisis has led to an increased demand for evaluations of potential cost savings to health care systems without impacting the quality and safety of treatment, and budget impact analyses showing the economic consequences of different treatments may be highly relevant or even warranted for health care decision-makers. This study compared the economic consequences of treating patients with grass pollen-induced allergic rhinoconjunctivitis using either grass AIT or grass SCIT.

\section{Materials and methods Health economic analysis}

A model was constructed to compare the budget impact of two standard immunotherapy treatments, ie, SQ-standardized grass AIT (Grazax ${ }^{\circledR}$; Phleum pratense, 75,000 SQ-T/2,800 BAU; ALK, Denmark) and grass SCIT (Alutard; P. pratense, 100,000 SQ-U; ALK, Denmark). The model was developed based on clinical data ${ }^{21}$ and a recently published metaanalysis, ${ }^{22}$ and all calculations were performed using Microsoft Office Excel 2007 (Microsoft, Redmond, WA).

The methodology for developing the budget impact analysis followed international health economic guidelines for budget impact analyses. ${ }^{23}$ According to these guidelines, a budget impact analysis should define scenarios relevant to health care decision-makers, the perspective should be that of the budget-holder, and the outcome of the analysis should reflect scenarios of interest to the decision-maker rather than assumptions intended to be generally applicable. Therefore, our budget impact analysis included calculation of all marginal costs from a Danish health care perspective to estimate possible annual savings to health care budgets resulting from implementation of grass AIT instead of grass SCIT. The analysis also included patient and societal costs, and reported these costs separately.

\section{General model assumptions}

The economic evaluation was conducted from a Danish health care perspective and included allergy treatment for adults in both the primary and secondary sector in Denmark. The analysis included direct treatment costs (cost of medication and physician visits), direct patient costs (travel expenses), and indirect patient costs (time lost). In accordance with Danish guidelines, ${ }^{24}$ a discount rate of $3 \%$ per year was applied to account for treatment duration of 3-5 years. General model assumptions are outlined in Table 1.

\section{Resource use}

Resources in terms of medication use, physician visits, and patient time were calculated and are outlined in Table 2. Health care utilization was calculated based on data collected from a review of clinical trials and standard treatment in Denmark (according to the Summary of Product Characteristics), and where data were limited, these were validated by medical experts. Expert validation was obtained from two structured workshops with Danish physicians. The wide variability in the participating physicians' specialties is considered to contribute to the robustness of the analysis. 
Table I General model assumptions

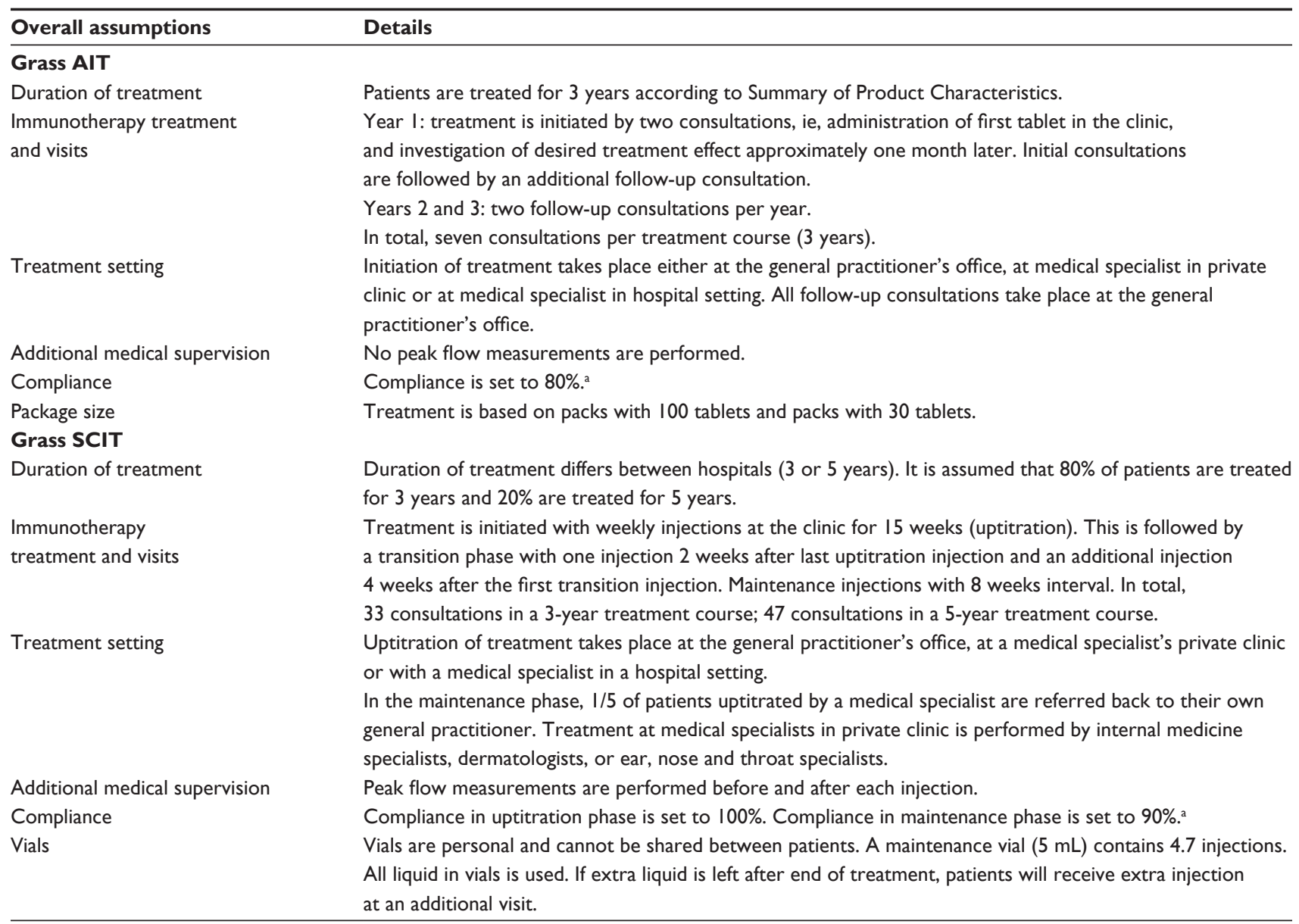

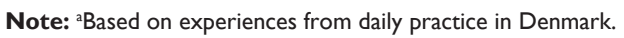

Abbreviations: AIT, allergy immunotherapy tablets; SCIT, subcutaneous immunotherapy.

\section{Costs}

Cost estimates are outlined in Table 3. Unit costs were obtained from established Danish public sources, including the Danish federal statistical office (Statistics Denmark), fees for service remuneration, and product list prices. ${ }^{25-29}$ All costs are reported in 2010 prices except when otherwise stated. Costs were obtained in Danish kroner and exchanged to Euro using the average 2010 exchange rate $(1$ Euro $=7.447366$ DKK).

\section{Sensitivity analysis}

The robustness of the budget impact analysis was investigated using a one-way sensitivity analysis. The most sensitive resource costs were systematically calculated to investigate the sensitivity of the overall result. The sensitivity analysis was based on direct treatment costs.

\section{Results}

\section{Treatment-related costs}

The result of the budget impact analysis is shown in Table 4. Direct treatment costs for treatment with grass SCIT were estimated to be $€ 4555$ per patient for a treatment course. In comparison, the direct treatment costs for treatment with grass AIT were estimated to be $€ 3264$ per patient for a treatment course, representing a cost saving of $€ 1291$ per patient. Estimated direct and indirect patients costs were $€ 2694$ for treatment with grass SCIT and $€ 525$ for treatment with grass AIT, representing a cost saving in total patient costs of $€ 2169$. Total savings (treatment costs and patient costs) amounted to $€ 3460$. This corresponds to a decrease of $28 \%$ in direct treatment costs, a decrease of $81 \%$ in direct and indirect patient costs, and a decrease in total costs of $48 \%$, if treatment with grass AIT is used instead of grass SCIT (Figure 1).

The cost savings gained by prescribing grass AIT instead of grass SCIT may be utilized to treat more patients with immunotherapy. In Figure 2, the relationship is shown between the number of subjects treated with grass AIT instead of grass SCIT, cost savings when using grass AIT instead of grass SCIT, and the number of new patients who could possibly be started on grass AIT without any additional cost as compared with the current costs for grass SCIT. As shown, it is 
Table 2 Resource use (health care utilization)

\begin{tabular}{|c|c|c|c|c|c|c|}
\hline Resource category & Resource type & Year I & Year 2 & Year 3 & Year 4 & Year 5 \\
\hline \multicolumn{7}{|l|}{ Grass AIT } \\
\hline Medication & Number of tablets (tablet/day $\times$ compliance) ${ }^{a}$ & 292 & 292 & 292 & - & - \\
\hline \multirow[t]{8}{*}{ Physician } & Number of initial visits (visit/year) ${ }^{b}$ & 2 & - & - & - & - \\
\hline & Treatment by general practitioner & 0.2 & - & - & - & - \\
\hline & Treatment in private clinic & 1.6 & - & - & - & - \\
\hline & Treatment in hospital setting & 0.2 & - & - & - & - \\
\hline & Number of follow-up visits (visit/year)c & 1 & 2 & 2 & - & - \\
\hline & Treatment by general practitioner & I & 2 & 2 & - & - \\
\hline & Treatment in private clinic & - & - & - & - & - \\
\hline & Treatment in hospital setting & - & - & - & - & - \\
\hline \multirow[t]{2}{*}{ Patient } & Travel distance $(\mathrm{km} / \mathrm{visit})^{\mathrm{d}}$ & 30 & 20 & 20 & - & - \\
\hline & Time lost (hours/visit) & 6 & 4 & 4 & - & - \\
\hline \multicolumn{7}{|l|}{ Grass SCIT } \\
\hline \multirow[t]{4}{*}{ Medication } & Number of uptitration kits & I & - & - & - & - \\
\hline & Number of maintenance vials needed (actual) ${ }^{f}$ & 1.06 & 0.34 & 0.83 & 1.11 & 0.60 \\
\hline & Number of maintenance vials needed (rounded) ${ }^{g}$ & 2 & I & I & 2 & I \\
\hline & Remaining injections in opened vial at the end of the yearh & 4.4 & 3.1 & 0.8 & 4.2 & 1.9 \\
\hline \multirow[t]{3}{*}{ Physician } & Uptitration visits & 15 & - & - & - & - \\
\hline & Maintenance visits & 5 & 6 & 7 & 6 & 8 \\
\hline & Number of peak flow measurementsi & 10 & 12 & 14 & 12 & 16 \\
\hline \multirow[t]{2}{*}{ Patient } & Travel distance $(\mathrm{km} / \mathrm{visit})^{d}$ & 200 & 60 & 70 & 60 & 80 \\
\hline & Time lost (hours/visit) ${ }^{\mathrm{e}}$ & 40 & 12 & 14 & 12 & 16 \\
\hline
\end{tabular}

Notes: ${ }^{a}$ One tablet/day; compliance $=80 \%$; ${ }^{b}$ two initial visits; ' $\mathrm{O}$ ne follow-up visit Ist year; 2 follow-up visits the following years; ${ }^{\mathrm{d}} \mathrm{l} 0 \mathrm{~km} / \mathrm{visit}$ based on experiences from daily practice in Denmark; ${ }^{2}$ hours/visit based on experiences from daily practice in Denmark; f́number of maintenance visits (injections)/no of injections per maintenance vial; ie, no of maintenance visits (injections)/4.7; g number of maintenance vials rounded to nearest whole vial; ${ }^{h}$ [number of maintenance vial needed (rounded) - number of maintenance vials (actual)] $\times$ number of injections per maintenance vial. Remaining injections in opened vial at the end of the year are used in the following year; 'peak flow measurements are performed before and after each injection. Peak flow measurements are included in medical specialist costs (private clinic/hospital setting), but not in general practice costs. Because general practitioners perform part of the maintenance visits, peak flow measurements are calculated based on number of maintenance visits.

Abbreviations: AIT, allergy immunotherapy tablets; SCIT, subcutaneous immunotherapy.

Table 3 Cost input (in €)

\begin{tabular}{|c|c|c|c|}
\hline Cost category & Cost type & Unit & Cost/unit \\
\hline \multicolumn{4}{|l|}{ Medication } \\
\hline \multirow[t]{3}{*}{ Grass AIT } & Pack with 30 tablets & Per tablet & 3.78 \\
\hline & Pack with 100 tablets & Per tablet & 3.40 \\
\hline & Average price, model assumption ${ }^{\mathrm{a}}$ & Per tablet & 3.48 \\
\hline \multirow[t]{2}{*}{ Grass SCIT } & Uptitration kit & Per uptitration & 233.80 \\
\hline & Maintenance & Per vial (5 mL) & 224.40 \\
\hline \multicolumn{4}{|l|}{ Physician visits } \\
\hline \multirow[t]{2}{*}{ General practitioners } & Visit & Per visit & 17.38 \\
\hline & Peak flow measurement & Per measurement & 4.87 \\
\hline \multirow[t]{6}{*}{ Medical specialists in private clinic $^{b}$} & First visit & Per visit & 78.86 \\
\hline & Second visit & Per visit & 52.43 \\
\hline & Consecutive visit & Per visit & 19.34 \\
\hline & First visit including fees ${ }^{c}$ & Per visit & 113.49 \\
\hline & Second visit including fees ${ }^{c}$ & Per visit & 87.05 \\
\hline & Consecutive visit including fees & Per visit & 53.97 \\
\hline \multirow[t]{3}{*}{ Medical specialists in hospital setting } & Outpatient visit & Per visit & 170.66 \\
\hline & Additional costs, uncomplicated allergy treatment & Per visit & 384.03 \\
\hline & Additional costs, complicated allergy treatment & Per visit & 528.11 \\
\hline \multicolumn{4}{|l|}{ Patient costs } \\
\hline Work & Lost working hours ${ }^{d}$ & Per hour & 36.16 \\
\hline Travel & Travel by private car & Per km & 0.48 \\
\hline
\end{tabular}

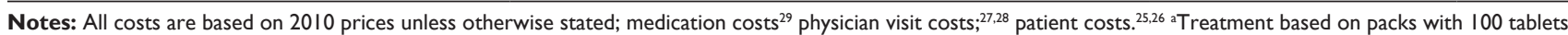
$(80 \%)$ and pack with 30 tablets (20\%); ${ }^{b}$ medical specialist costs (private clinic) are based on a weighted average of consultation fees for internal medicine specialists, dermatologists and ear, nose and throat specialists; 'fees include peak flow measurements and fee for injection; dost working hours are based on the mean salary/hour for the general population aged 18-65 years in Denmark including the unemployed.

Abbreviations: AIT, allergy immunotherapy tablets; SCIT, subcutaneous immunotherapy. 
Table 4 Costs (in $€$ ) in relation to treatment with grass AIT and grass SCIT

\begin{tabular}{|c|c|c|c|c|c|c|c|}
\hline Cost category & Resource type & Year I & Year 2 & Year 3 & Year 4 & Year 5 & Total \\
\hline \multicolumn{8}{|l|}{ Grass AIT } \\
\hline \multirow[t]{5}{*}{ Direct treatment costs } & Medication (tablets) & 1014 & 985 & 956 & - & - & 2955 \\
\hline & Physician visits & 242 & 34 & 33 & - & - & 309 \\
\hline & Treatment by GP & 21 & 34 & 33 & - & - & 88 \\
\hline & Treatment in private clinic & 110 & - & - & - & - & 110 \\
\hline & Treatment in hospital setting & 111 & - & - & - & - & 111 \\
\hline Direct treatment costs, total & & 1256 & 1019 & 989 & - & - & 3264 \\
\hline Direct patient costs & Travel expenses & 14 & 9 & 9 & - & - & 32 \\
\hline Direct treatment + patient costs, total & & 1270 & 1028 & 998 & - & - & 3296 \\
\hline Indirect costs & Patient productivity (time lost) & 217 & 140 & 136 & - & - & 493 \\
\hline Total costs & & 1487 & 1168 & 1134 & - & - & 3789 \\
\hline \multicolumn{8}{|l|}{ Grass SCIT } \\
\hline \multirow[t]{5}{*}{ Direct treatment costs } & Medication (uptitration kits) & 234 & - & - & - & - & 234 \\
\hline & Medication (maintenance vials) & 449 & 218 & 212 & 82 & 40 & 1001 \\
\hline & Physician visits & 2027 & 504 & 571 & 95 & 123 & 3320 \\
\hline & Uptitration visits & 1594 & - & - & - & - & 1594 \\
\hline & Maintenance visits & 433 & 504 & 571 & 95 & 123 & 1726 \\
\hline Direct treatment costs, total & & 2710 & 722 & 783 & 177 & 163 & 4555 \\
\hline Direct patient costs & Travel expenses & 96 & 28 & 32 & 5 & 7 & 168 \\
\hline Direct treatment + patient costs, total & & 2806 & 750 & 815 & 182 & 170 & 4723 \\
\hline Indirect costs & Patient productivity (time lost) & 1446 & 421 & 477 & 79 & 103 & 2526 \\
\hline Total costs & & 4252 & 1171 & 1,292 & 261 & 273 & 7249 \\
\hline Cost reduction (grass AIT - grass SCIT) & & -2765 & -3 & -158 & -261 & -273 & -3460 \\
\hline
\end{tabular}

Note: Costs include $3 \%$ discount.

Abbreviations: AIT, allergy immunotherapy tablets; SCIT, subcutaneous immunotherapy.

possible to treat a substantial number of new patients on grass AIT without any additional cost to the health care system. For example, if 1500 subjects were treated with grass AIT instead of grass SCIT, it would be possible to treat approximately 600 more patients per year without increasing the current costs to the health care system. This corresponds to an increase in the number of treated patients of approximately $40 \%$.

\section{Sensitivity analysis}

The results of the one-way sensitivity analysis are shown in Table 5. The basic treatment cost saving was $€ 1291$. Resource

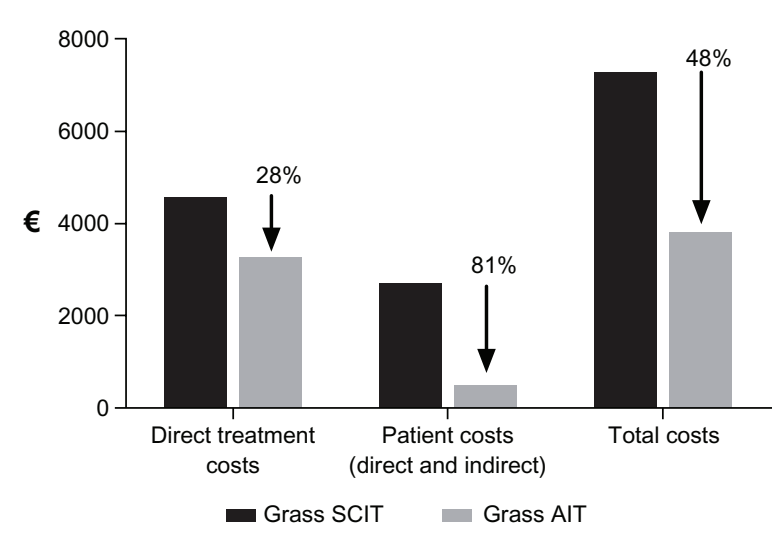

Figure I Decrease in direct treatment costs, patients costs and total costs in relation to treatment with grass AIT as compared with grass SCIT.

Abbreviations: AIT, allergy immunotherapy tablets; SCIT, subcutaneous immunotherapy. costs were varied in both directions and, regardless of variation/adjustment, all costs were in favor of grass AIT with incremental costs for grass SCIT. Notably, variations between the general practice and hospital settings resulted in major changes in direct treatment costs, whereas the discount rate and duration of treatment had no or at least less impact on the analysis.

\section{Discussion}

A budget impact analysis compares the costs of different treatment options seen from a health care decision-maker

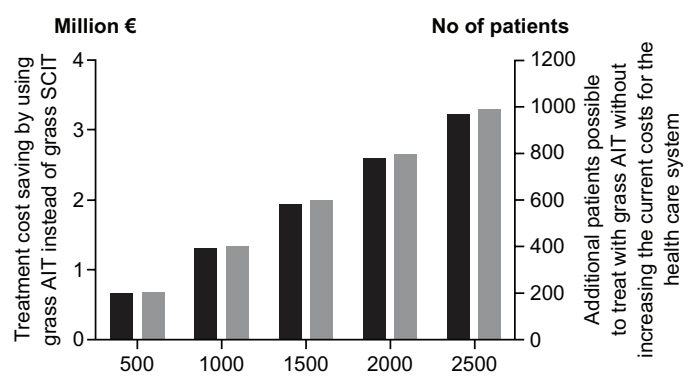

Number of patients treated with grass AIT instead of grass SCIT

- Treatment cost saving by using grass AIT instead of grass SCIT

- Additional patients possible to treat with grass AIT without increasing the current costs for the health care system

Figure 2 Relationship between number of patients treated with immunotherapy, treatment costs savings and possibility to initiate additional patients on grass AIT without increasing the current health care budget.

Abbreviations: AIT, allergy immunotherapy tablets; SCIT, subcutaneous immunotherapy. 
Table 5 One-way sensitivity analysis (direct treatment costs, in $€$ )

\begin{tabular}{|c|c|c|}
\hline Sensitivity analysis & $\begin{array}{l}\text { Mean direct treatment } \\
\text { costs }(€) \text {, grass AIT }\end{array}$ & $\begin{array}{l}\text { Mean and incremental direct treatment costs }(€) \text {, } \\
\text { grass SCIT (difference from grass AIT) }\end{array}$ \\
\hline \multicolumn{3}{|l|}{ General } \\
\hline Base case & 3264 & $4555(+|29|)$ \\
\hline \multicolumn{3}{|l|}{ Discount rate } \\
\hline $0 \%$ & 3354 & $4660(+1306)$ \\
\hline $5 \%$ & 3207 & $4489(+1282)$ \\
\hline \multicolumn{3}{|l|}{ Grass AIT } \\
\hline Base case & 3264 & $4555(+\mid 291)$ \\
\hline \multicolumn{3}{|l|}{ Initiation of treatment } \\
\hline 100\% hospital setting & 4148 & $4555(+407)$ \\
\hline $100 \%$ general practice & 3074 & $4555(+1480)$ \\
\hline \multicolumn{3}{|l|}{ Follow-up treatment } \\
\hline As for grass SCIT & 3490 & $4555(+1065)$ \\
\hline $100 \%$ general practice & 3264 & $4555(+\mid 291)$ \\
\hline \multicolumn{3}{|l|}{ Number of visits/year } \\
\hline $4+3+3$ & 3314 & $4555(+\mid 24 I)$ \\
\hline $2+1+1$ & 3213 & $4555(+1342)$ \\
\hline \multicolumn{3}{|l|}{ Compliance } \\
\hline $100 \%$ & 4002 & $4555(+553)$ \\
\hline $60 \%$ & 2525 & $4555(+2030)$ \\
\hline \multicolumn{3}{|l|}{ Duration of treatment } \\
\hline As for grass SCIT & 3688 & $4555(+867)$ \\
\hline 3 years & 3264 & $4555(+\mid 291)$ \\
\hline \multicolumn{3}{|l|}{ Grass SCIT } \\
\hline Base case & 3264 & $4555(+\mid 291)$ \\
\hline \multicolumn{3}{|c|}{ Injections extracted per vial } \\
\hline$+20 \%$ & 3264 & $4515(+|25|)$ \\
\hline$-20 \%$ & 3264 & $4836(+1572)$ \\
\hline \multicolumn{3}{|l|}{ Uptitration visits } \\
\hline $100 \%$ hospital setting & 3264 & $11,280(+8016)$ \\
\hline $100 \%$ general practice & 3264 & $3366(+102)$ \\
\hline \multicolumn{3}{|l|}{ Maintenance visits } \\
\hline $100 \%$ hospital setting & 3264 & $|3,89|(+\mid 0,627)$ \\
\hline $100 \%$ general practice & 3264 & $3369(+105)$ \\
\hline \multicolumn{3}{|c|}{ Number of weeks between injections } \\
\hline 10 weeks & 3264 & $3996(+732)$ \\
\hline 6 weeks & 3264 & $530 I(+2037)$ \\
\hline \multicolumn{3}{|c|}{ Compliance, uptitration } \\
\hline $100 \%$ & 3264 & $4555(+\mid 291)$ \\
\hline $80 \%$ & 3264 & $4250(+986)$ \\
\hline \multicolumn{3}{|c|}{ Compliance, maintenance } \\
\hline $100 \%$ & 3264 & $4557(+1293)$ \\
\hline $70 \%$ & 3264 & $4233(+969)$ \\
\hline \multicolumn{3}{|l|}{ Duration of treatment } \\
\hline $0 \%$ treated for 5 years $^{\mathrm{a}}$ & 3264 & $4214(+950)$ \\
\hline $40 \%$ treated for 5 years & 3264 & $4894(+1630)$ \\
\hline
\end{tabular}

Note: aAll patients treated for 3 years.

Abbreviations: AIT, allergy immunotherapy tablets; SCIT, subcutaneous immunotherapy.

perspective. Therefore, the focus of this budget impact analysis was to compare the economic consequences of treating patients with grass pollen-induced allergic rhinitis using either grass AIT or grass SCIT.

The analysis showed that overall direct treatment costs as well as patient costs were lower for treatment with grass
AIT than for treatment with grass SCIT. The main cost difference between the two treatments was the result of fewer physician visits being needed for grass AIT as compared with grass SCIT. The cost of medication per patient was higher for grass AIT as compared with grass SCIT, whereas the costs of physician visits, travel expenses, and lost working hours 
were considerably lower for grass AIT. The overall impact was reduced costs for the health care system and society (reduced physician visits and resources) as well as for individual patients (reduced travel expenses and less lost working hours). The robustness of these results was confirmed by the one-way sensitivity analysis.

The total treatment cost saving to the health care system amounted to $€ 1291$ per patient per treatment course when using grass AIT instead of grass SCIT. In 2010, approximately 1200 patients were initiated on grass SCIT treatment in Denmark (data on file). Assuming a similar continuous number of patients initiating immunotherapy treatment per year in the future, the implication for Danish society will be a treatment cost saving of more than $€ 1,500,000$ on a yearly basis if grass AIT is used as treatment instead of grass SCIT. Cost saving in this range implies that more than 450 additional patients per year could be treated with grass AIT without influencing costs. An increase in the number of patients treated per year may have additional beneficial outcomes for the health care system both in terms of additional cost savings as well as in terms of improved health status for patients. Allergic rhinitis is an independent risk factor for development of asthma. ${ }^{5}$ Because asthma is a disease with considerable burden and substantial costs to both the public and private health care systems, ${ }^{30}$ the potential cost savings to the health care system may be even more pronounced if patients with grass pollen-induced allergic rhinitis are treated with grass immunotherapy. In addition, having more patients on immunotherapy may decrease the use of other kinds of medication used for treatment of allergic rhinitis and/or asthma, thereby decreasing costs to the health care system in relation to these medications. Grass AIT also has a number of other advantages which may be beneficial for the health care system, but which are not included in the budget impact analysis per se.

Grass AIT is generally considered to have a significantly lower risk profile than SCIT. ${ }^{31,32}$ The potentially lower costs for treatment of adverse events resulting from AIT are not considered in this analysis. The main cost related to side effects and seen from a health care decision-maker perspective is for hospitalization. Hospital admissions due to side effects of immunotherapy are considered to be uncommon but, because no firm documentation on the extent of these admissions is available, they have not been addressed in this study.

Treatment with grass AIT is also simpler and more convenient than for grass SCIT because tablets can be administered at home instead of injections at a clinic. Home administration will, as mentioned above, result in fewer physician visits as compared with grass SCIT, and thereby lead to cost savings to the health care system. However, home administration is often perceived to be related to lower compliance than that achieved when treatment is given in a specialist office, leading to lower efficacy of treatment. However, a recent study evaluating compliance with grass AIT and grass SCIT indicated that compliance with both treatments was high and comparable ( $\geq 80 \%){ }^{33}$

Grass AIT has also been shown to have a sustained and disease-modifying effect. ${ }^{14,21}$ This may lead to additional cost savings for both the individual patient and for society as a whole in terms of improved quality of life and lower costs related to absenteeism from work and decreased productivity.

Because several of the aforementioned factors are not included in the budget impact analysis due to limited data, a more comprehensive economic evaluation may be warranted to evaluate the overall health economic consequences of using grass AIT instead of grass SCIT. Further evaluation may include a cost-utility analysis to obtain data on quality of life for patients and a cost-benefit analysis to obtain data on willingness to pay.

\section{Conclusion}

In conclusion, this budget impact analysis shows that grass AIT is a cost-saving alternative to grass SCIT when treating patients with grass pollen-induced allergic rhinitis. Seen from a health care perspective, grass AIT represents an efficient use of cost and resources. Further analyses may be warranted to evaluate the overall health economic consequences of implementation of grass AIT instead of grass SCIT.

\section{Disclosure}

This health economic evaluation was funded by ALK, Denmark. SMR, UGS, JSM, LY, and LE have received grants from ALK. JNA is employed at ALK. The authors thank Anne Okkels Birk, who provided medical writing, editorial, and journal submission assistance on behalf of ALK.

\section{References}

1. Bauchau V, Durham SR. Prevalence and rate of diagnosis of allergic rhinitis in Europe. Eur Respir J. 2004;24:758-764.

2. Dahl R, Andersen P, Chivato T, Valovirta E, de Monchy J. National prevalence of respiratory allergic disorders. Respir Med. 2004;98: 398-403

3. Weiss KB, Sullivan SD. The health economics of asthma and rhinitis. I. Assessing the economic impact. J Allergy Clin Immunol. 2001;107:3-8.

4. Schatz M. A survey of the burden of allergic rhinitis in the USA. Allergy. 2007;62 Suppl 85:9-16. 
5. Nathan RA. The burden of allergic rhinitis. Allergy Asthma Proc. 2007;28:3-9.

6. Walker S, Khan-Wasti S, Fletcher M, Cullinan P, Harris J, Sheikh A. Seasonal allergic rhinitis is associated with a detrimental effect on examination performance in United Kingdom teenagers: case-control study. J Allergy Clin Immunol. 2007;120:381-387.

7. Vuurman EF, van Veggel LM, Uiterwijk MM, Leutner D, O'Hanlon JF. Seasonal allergic rhinitis and antihistamine effects on children's learning. Ann Allergy. 1993;71:121-126.

8. Sundberg R, Toren K, Hoglund D, Aberg N, Brisman J. Nasal symptoms are associated with school performance in adolescents. J Adolesc Health. 2007;40:581-583.

9. Bousquet J, Khaltaev N, Cruz AA, et al. Allergic Rhinitis and its Impact on Asthma (ARIA) 2008 update (in collaboration with the World Health Organization, GA(2)LEN and AllerGen). Allergy. 2008;63 Suppl $86: 8-160$.

10. Plaut M, Valentine MD. Clinical practice. Allergic rhinitis. $N$ Engl $J$ Med. 2005;353:1934-1944

11. European Medicines Agency. Guideline on the clinical development on products for specific immunotherapy for the treatment of allergic diseases. 2008. CHMP/EWP/18504/2006.

12. Frew AJ, Powell RJ, Corrigan CJ, Durham SR. Efficacy and safety of specific immunotherapy with SQ allergen extract in treatmentresistant seasonal allergic rhinoconjunctivitis. JAllergy Clin Immunol. 2006;117:319-325.

13. Durham SR, Walker SM, Varga EM, et al. Long-term clinical efficacy of grass-pollen immunotherapy. $N$ Engl J Med. 1999;341:468-475.

14. Durham S, Emminger W, Kapp A, et al. Disease-modifying effect of the SQ-standardised grass allergy immunotherapy tablet is sustained 2 years after treatment. Allergy. 2010;65:689-690.

15. Dahl R, Stender A, Rak S. Specific immunotherapy with SQ standardized grass allergen tablets in asthmatics with rhinoconjunctivitis. Allergy. 2006;61:185-190.

16. Dahl R, Kapp A, Colombo G, et al. Efficacy and safety of sublingual immunotherapy with grass allergen tablet for seasonal allergic rhinoconjunctivitis. J Allergy Clin Immunol. 2006;118:434-440.

17. Dahl R, Kapp A, Colombo G, et al. Sublingual grass allergen tablet immunotherapy provides sustained clinical benefit with progressive immunologic changes over 2 years. J Allergy Clin Immunol. 2008;121:512-518.

18. Frølund L, Durham SR, Calderon M, et al. Sustained effect of SQstandardized grass allergy immunotherapy tablet on rhinoconjunctivitis quality of life. Allergy. 2010;65:753-757.

19. Nelson HS, Nolte H, Creticos P, Maloney J, Wu J, Bernstein DI. Efficacy and safety of timothy grass allergy immunotherapy tablet treatment in North American adults. J Allergy Clin Immunol. 2011;127:72-80.

20. Blaiss M, Maloney J, Nolte H, Gawchik S, Yao R, Skoner DP. Efficacy and safety of Timothy grass allergy immunotherapy tablets in North American children and adolescents. J Allergy Clin Immunol. 2011;127:64-71.

21. Durham SR, Emminger W, Kapp A, et al. Long-term clinical efficacy in grass pollen-induced rhinoconjunctivitis after treatment with SQ-standardized grass allergy immunotherapy tablet. J Allergy Clin Immunol. 2010;125:131-138.
22. Calderon M, Andersen JS, Lawton S. Meta-analysis supports that the efficacy of grass allergy immunotherapy tablets is comparable to subcutaneous immunotherapy. Allergy. 2011;Suppl 94:652-653.

23. Mauskopf JA, Sullivan SD, Annemans L, et al. Principles of good practice for budget impact analysis: report of the ISPOR Task Force on good research practices - budget impact analysis. Value Health. 2007; 10:336-347.

24. Danish Medicines and Health Authority. Erfaringer med sundhedsøkonomiske analyser i ansøgninger om generelt tilskud til lægemidler. 2004. [Danish Medicines and Health Authority. Experiences with health economic analyses in drug reimbursement applications. 2004.]. Available from: http://laegemiddelstyrelsen.dk/ da/topics/statistik,-priser-og-tilskud/tilskud-til-medicin/generelletilskud/ansoegning/sundhedsoekonomiske-analyser/erfaringer-medsundhedsoekonomiske-analy-aegemidler. Accessed July 15, 2012. Danish.

25. Danish Tax and Customs Administration. Skattesatser 2009-2012. [Tax rates 2009-2012.]. Available from: http://skat.dk/SKAT.aspx?oId=2035 $568 \&$ vId $=0 \&$ prev $=2010 \&$ tab $=$. Accessed July 15, 2012. Danish.

26. Statistics Denmark. Earnings. Available from: http://iisboy4.dst.dk/ statbank $5 \mathrm{a} /$ SelectTable/omrade0.asp? Subjectcode $=17 \&$ PLanguage $=1$ \&Shownews=OFF\&tree=false. Accessed July 15, 2012.

27. National Board of Health Denmark. Takstsystem 2010 Vejledning (DAGS fees). [System of charges 2010 instruction (DAGS fees).]. Available from: http://www.sst.dk/publ/Publ2010/SESE/Takst/Takstvejledning_\%202010.pdf. Accessed July 15, 2012. Danish.

28. Danish Medical Association. $\$ 56$ Ydelser i dagtiden (wage and fees). [\$56 Day time payments (wage and fees).]. Available from: http://www. laeger.dk/portal/page/portal/LAEGERDK/Laegerdk/P_L_O/Overenskomster/Honorartabel/Honorartabel $\% 201-204-12 / \% \mathrm{C} 2 \% \mathrm{~A} 7 \% 20$ 56\%20Ydelser\%20i\%20dagtiden1. Accessed July 15, 2012. Danish.

29. Danish Medicines and Health Authority. List of medicine prices. Available from: http://www.medicinpriser.dk/; http://laegemiddelstyrelsen.dk/da/topics/statistik,-priser-og-tilskud/priser-paa-medicin/ prisudvikling/priser-de-seneste-5-aar. Accessed July 15, 2012.

30. GINA Executive Committee. Global Initiative for Asthma; Global Strategy for Asthma Management and Prevention, 2009. Bethesda, MD: National Heart, Lung and Blood Institute, National Institute of Health; 2009.

31. Radulovic S, Calderon MA, Wilson D, Durham S. Sublingual immunotherapy for allergic rhinitis. Cochrane Database Syst Rev. 2010;12:CD002893.

32. Passalacqua G, Compalati E, Canonica GW. Sublingual immunotherapy for allergic rhinitis: an update. Curr Opin Otolaryngol Head Neck Surg. 2011;19:43-47.

33. Andreasen JN, Lawton S, Bæch SB, Svärd M. Compliance and persistence to grass immunotherapy treatment is comparable for allergy immunotherapy tablets and subcutaneous immunotherapy: a Swedish registry study. Abstract presented at World Allergy Congress, December 4-8, 2011, Cancun, Mexico.
ClinicoEconomics and Outcomes Research

\section{Publish your work in this journal}

ClinicoEconomics \& Outcomes Research is an international, peerreviewed open-access journal focusing on Health Technology Assessment, Pharmacoeconomics and Outcomes Research in the areas of diagnosis, medical devices, and clinical, surgical and pharmacological intervention. The economic impact of health policy and health systems
Dovepress

organization also constitute important areas of coverage. The manuscript management system is completely online and includes a very quick and fair peer-review system, which is all easy to use. Visit http://www.dovepress.com/testimonials.php to read real quotes from published authors. 